\title{
Cytotoxicity, Removal of Congo Red Dye in Aqueous Solution Using Synthesized Amorphous Iron Oxide Nanoparticles from Incense Sticks Ash Waste
}

\author{
Virendra Kumar Yadav $\mathbb{D}^{1},{ }^{1}$ G. Gnanamoorthy $\mathbb{D}^{\mathbb{D}},{ }^{2}$ Daoud Ali, ${ }^{3}$ Sweta Parimita Bera $\mathbb{D}^{1},{ }^{1}$ \\ Arpita Roy ${ }^{\mathbb{D}},{ }^{4}$ Gokhlesh Kumar, ${ }^{5}$ Nisha Choudhary ${ }^{(D},{ }^{6}$ Haresh Kalasariya, ${ }^{7}$ \\ and Anup Basnet $\mathbb{D}^{8}$ \\ ${ }^{1}$ Department of Microbiology, School of Sciences, P P Savani University, Surat, 394125 Gujarat, India \\ 2 ..Department of Inorganic Chemistry, University of Madras, Guindy Campus, -600025, T, N, Chennai, India \\ ${ }^{3}$ Department of Zoology, College of Science, King Saud University, PO Box 2455, Riyadh 11451, Saudi Arabia \\ ${ }^{4}$ Department of Biotechnology, School of Engineering \& Technology, Sharda University, Greater Noida, India \\ ${ }^{5}$ Clinical Division of Fish Medicine, University of Veterinary Medicine, Vienna, 1210 Vienna, Austria \\ ${ }^{6}$ Department of Environment Sciences, School of Sciences, P P Savani University, Surat, 394125 Gujarat, India \\ ${ }^{7}$ Department of Microbiology, Sankalchnad Patel University, 382015 Mehsana, Gujarat, India \\ ${ }^{8}$ Department of Microbiology, Saint Xaviers College, Maitighar, Kathmandu 695586, Nepal \\ Correspondence should be addressed to Anup Basnet; basnet.a@sxc.edu.np
}

Received 13 January 2022; Revised 29 January 2022; Accepted 1 February 2022; Published 14 February 2022

Academic Editor: Palanivel Velmurugan

Copyright (C) 2022 Virendra Kumar Yadav et al. This is an open access article distributed under the Creative Commons Attribution License, which permits unrestricted use, distribution, and reproduction in any medium, provided the original work is properly cited.

\begin{abstract}
Magnetic nanoparticles have gained huge importance in the last ten years. They have found tremendous applications in the field of medicine, electronics, and environmental cleanup. The synthesis of amorphous iron oxide nanoparticles (AIONPs) is expensive making its applications highly overpriced. This research study reports the synthesis of AIONPs from waste incense sticks ash (ISA) in two steps. The first step is the recovery of ferrous fractions from ISA, followed by concentrated $\mathrm{HCl}$ treatment of magnetic fraction along with ultrasonication. And the second step includes treatment of ferrous-rich leachate with sodium hydroxides. The size of synthesized AIONPs varied from $40-90 \mathrm{~nm}$ and were highly aggregated due to the formation of large clumps. Cytotoxicity of synthesized AIONPs was determined on a normal human lung (BEAS-2B) cell line by using an MTT assay. Data showed that AIONPs induced cell toxicity in a dose-dependent manner. The particles were mainly spherical to rod-shaped and highly aggregated, it was confirmed by the microscopy analysis. The Fourier transform infrared (FT-IR) and Raman spectroscopy revealed the $\mathrm{Fe}-\mathrm{O}, \mathrm{Si}-\mathrm{O}-\mathrm{Al}$ as major functional groups in the AIONPs, while X-ray diffraction (XRD) revealed the amorphicity and physical property measurement system (PPMS) revealed the magnetic strength of the synthesized AIONPs. Finally, the AIONPs particles were applied for the remediation of Congo red dye from the wastewater by the adsorption method, and about $72 \%$ removal was achieved after one hour. The utilization of such ISA waste, for the synthesis of value-added minerals and their utilization for environmental cleanup, makes this whole process cost-efficient and environment-friendly.
\end{abstract}

\section{Introduction}

Nanoparticles (NPs) and nanotechnology have drawn the attention of the whole world in the last few decades. They are known to have remarkable phenomena at the nanoscale in comparison to the bulk materials [1-4]. Out of all the NPs, magnetic NPs are extensively applied in the field of medicine [5], environmental cleanup, and research [6, 7]. The ferrous-based iron oxide nanoparticles (IONPs) have numerous advantages over other magnetic particles $(\mathrm{Ni}$, 
Co, etc.) [8]. Magnetite has both ferrous and ferric ions, and IONPs have both crystalline and amorphous forms. This is the reason for IONPs being widely used in both medicine [9] and environmental remediation [10]. Among the crystalline and amorphous forms of iron oxide [11], the latter one has a specific role in sensing [12], gas sorption [13], and electrode materials [14]. An amorphous iron oxide nanoparticle (AIONP) [15] has a larger surface area in comparison to the crystalline IONPs [16]. This is because the disturbed surface structure along with a huge number of unsaturated bonds enhances their catalytic activity and superparamagnetic behavior [17]. The current production of AIONPs employs the use of iron oxide particles. These are expensive and energy-intensive processes [18]. The synthesis of AIONPs from ferrous rich waste material acts as a sustainable and reliable source of AIONPs. The waste from iron and steel industries, iron scraps [19], coal fly ash (CFA) [20], bauxite [21, 22] and incense sticks ash [23] have an appreciable amount of ferrous which is already well proven in the literature $[24,25]$. Out of all these byproducts, ISA is one of the most overlooked by-product, especially in South Asian countries including India and Myanmar. In India, ISA is considered sacred and is mainly disposed into the rivers or water sources $[24,26]$. Earlier Yadav et al.,2020 [24] reported that ISA has 50-60\% oxides of calcium and magnesium and traces of heavy metals, which may pollute the freshwater [24]. Besides, calcium and magnesium ISA also have silica ( 20\%), ferrous, alumina 5-8\% each, several trace elements and numerous toxic heavy metals like $\mathrm{Cd}, \mathrm{Ni}, \mathrm{Co}, \mathrm{Cu}, \mathrm{As}, \mathrm{Mo}, \mathrm{Pb}, \mathrm{Hg}$ etc. [24, 27]. This is a potential challenge to the aquatic living organism in the aquatic systems and also to human beings. India is the fourth-largest producer of incense sticks and the thirdlargest consumer of incense sticks in the worldwide [15]. So, a huge amount of ferrous can be recovered from the ISA from India alone, though the exact amount of ISA production and generation is not available with Government. Until now, very few attempts have been made to utilize ISA for any scientific applications. An economical adsorbent for the removal of Victoria blue dye from the aqueous solutions by Jain et al., 2020 [28] is one study that has been reported. Another one is the synthesis of IONPs by Yadav et al., 2020 [24]. Both the authors reported that ISA is highly porous and thus it holds a promising role as an economical and efficient adsorbent for environmental cleanup. Yet there is no study conducted to recover the different components of ISA and utilize them for the synthesis of IONPs. So, to fill this gap this research study was conducted. Though numerous techniques have been applied for the synthesis of AIONPs, but sonochemical methods have certain advantages over techniques. The synthesis of AIONPs requires a high cooling rate which can be fulfilled only by sonochemical techniques. In this technique cooling rate can be achieved up to ten million degrees per second [29-32].

The natural water systems are heavily polluted with several textile dyes which are very harmful to the environment due to their toxigenic and carcinogenic properties [33]. One such diazo textile dye is Congo red (CR) which are the most widely textile dye. It is used to dye cotton [34], paper [35], calico printing [36], and most commonly in stain histological laboratories $[37,38]$. It is one of the most commonly used dyes for the visualization of amyloid fibers [39]. There are several reports where it has been found that even at very low concentration of CR dye it may affect the fertility of the organisms. For instance, Hernandez et al., 2016 [40] shown that even small concentration of CR dye may lead to infertility in the cladoceran Ceriodaphnia dubia [40]. Similarly, side effects of CR dye was also reported by Rani et al., 2017 [40, $41]$ in the aquatic system and suggested its removal by coconut shell as an adsorbent. So, there is an immediate requirement to remove such pollutants from our natural resources by a cost-effective technique. These pollutants can be remediated by the AIONPs by a simple adsorption technique making it much economical. The adsorbents used in the process are acquired from the waste material making it more utilizable. Though the ISA has shown high efficiency for the remediation of dyes, the exact component of ISA that played a major role in the adsorption process is still unknown.

The present research work focuses on the recovery of ferrous fractions from ISA, and the synthesis of highly pure AIONPs from the ferrous fractions by ultrasonication method. Further, synthesized IONPs were analyzed by analytical instruments for the confirmation of the formation of IONPs. Finally, the synthesized AIONPs were utilized for the removal of CR dye from the aqueous solutions at room temperature (RT). Such, practice will suggest an economical and alternative source of iron-based industries. Moreover, the AIONPs will be used as an effective nano adsorbent for the remediation of azo dye or acidic dye i.e. CR from the wastewater or environmental systems, under normal conditions. Finally, such type of work will suggest an alternative method for the safe disposal of ISA.

\section{Materials and Methods}

2.1. Chemical and Reagents. MTT [3-(4, 5-dimethylthiazol2-yl)-2, 5-diphenyltetrazolium bromide], was procured from Sigma-Aldrich (St. Louis, Missouri, United States). Dulbecco's modified Eagle's medium (DMEM), antibiotics and fetal bovine serum (FBS) procured from [Gibco, USA].

Incense sticks, Incense sticks ash (ISA), Conc. $\mathrm{HCl}$ (RENKEM), Sodium hydroxide pellets (Himedia, India), Congo red dye grains (Molychem, India), $100 \mathrm{ml}$ round bottom flask, Glass beaker (100 ml), Conical flask (250 ml), Petri plate, ethanol (Molychem, India) and distilled water.

2.2. Collection of ISA. Initially, the collection of ISA was done from the Temples situated in Sector, 30, Gandhinagar, Gujarat, India, in a plastic container. It is one of the major temples and produces a significant amount of ISA but their source was unknown as it has residues from various types of incense sticks, like coal powder-based black, coloured or, potassium nitrate-based white-coloured. So, further, black coloured incense sticks were purchased from the nearby market area (Gandhinagar, Gujarat, India) for carrying the experiments. The black colour combustible part was separated from the bamboo sticks. The obtained black coloured fraction was then powdered by using a grinder. The ground 
fine powder was then placed in a quartz crucible and placed in a muffle furnace (MF). The black-coloured fraction was combusted in the MF by gradually increasing the temperature at $10^{\circ} \mathrm{C}$ per five minutes and finally raised to $400^{\circ} \mathrm{C}$ for 6 hours. Finally, the incense sticks ash was weighed and stored in a container for future applications.

2.3. Recovery of Magnetic Fractions from ISA. About 50 grams of ISA was taken in a plastic beaker, and $200 \mathrm{ml}$ of double distilled water was poured to obtain a slurry. Further, a strong neodymium magnet was subjected to this slurry. This led to the collection of the ferrous fractions. The collected ferrous fractions were then detached from the magnet and oven-dried at $60^{\circ} \mathrm{C}$ for overnight. The ferrous fraction was weighed on a weighing balance.

2.4. Synthesis and Characterization of AIONPs. About 2 grams of dried ferrous fractions were taken in a round bottom flask and $20 \mathrm{ml}$ of conc. $\mathrm{H}_{2} \mathrm{SO}_{4}$ was added to it. This was then subjected to sonication at $70^{\circ} \mathrm{C}$ for 60 minutes. Once the reaction was finished, the reaction mixture was cooled at RT. The reaction mixture was then left to attain the RT and transferred to a Falcon tube for centrifugation at $5000 \mathrm{rpm}$ for 10 minutes. The yellowish color supernatant was poured into a beaker while the residue was washed, dried and stored for future analysis.

About $20 \mathrm{ml}$ of yellow-coloured $\mathrm{Fe}^{2+} / \mathrm{Fe}^{3+}$ rich leachate was taken in the round bottom flask. About $8 \mathrm{M} \mathrm{NaOH}$ aqueous solution was prepared separately and was added dropwise to the round bottom flask. When the mixture started to turn black to reddish-brown, further addition of $\mathrm{NaOH}$ was stopped. The mixture was placed in an ultrasonicator (Sonar, $40 \mathrm{kHz}$ ), at $60^{\circ} \mathrm{C}$ for 90 minutes. The mixture was left undisturbed for 90 minutes in the ultrasonicator at the above reaction conditions. Once the reaction was finished, the reaction mixture was cooled at RT. The mixture was then centrifuged at $5000 \mathrm{rpm}$ for 10 minutes. The supernatant was discarded, while washing of precipitate was done 2-3 times with double distilled water and ethanol separately. Finally, the precipitate was transferred to a Petri plate and oven-dried at $80^{\circ} \mathrm{C}$ till the precipitate got completely dried. The obtained reddish-brown powder was characterized by analytical instruments for the identification and purity of the synthesized AIONPs [26]. The AIONPs were analyzed by the Fourier- transform infrared (FTIR) using SP 65, Perkin Elmer, (Germany) [42] and Raman spectroscopy using Witec alpha $3600^{+}$, Germany. The FT-IR analysis was carried out in the infrared region of $400-4000 \mathrm{~cm}^{-1}$ at a resolution of $2 \mathrm{~cm}^{-1}$, while Raman spectroscopy were carried out by placing the AIONPs on a glass coverslip with a laser intensity of $625 \mathrm{~nm}$ and $750 \mathrm{~nm}$. The phase identification of the AIONPs were carried out by X-ray diffraction (XRD), using Bruker advance D-8, Focus P-XRD, Bruker (Germany) in the range of $\left(2 \theta\right.$ of $\left.20-70^{\circ}\right)$. The step size was 0.02 and a time of 5 seconds per step at $40 \mathrm{kV}$ voltage and a current of $30 \mathrm{~mA}$. The surface study and morphological features were studied by using Field emission scanning electron microscopy (FESEM), Nova,
NANOSEM 450 (FEI, Netherlands) [42], where the dried powder of AIONPs were placed on the carbon tape on an aluminum stub. The elemental analysis and purity of the AIONPs were analyzed by the attached Electron diffraction spectroscopy (EDS) (Bruker) with FESEM. Transmission scanning electron microscopy (TEM) of the AIONPs were done by using FEI Model Tecnai G2 20 Twin $(200 \mathrm{kV})$ [USA], and magnetic property of the synthesized AIONPs by Physical Property Measurement System (PPMS) Model, and atomic force microscopy (AFM) using Model XE-70, Perk systems. The AIONPS were assessed for the remediation of CR dye from the wastewater by the adsorption method.

2.5. Cells Culture and Exposure of AIONPs. Normal human lung (BEAS-2B) cell line (CAT NO. 95102433) [SigmaAldrich Chemie GmbH Eschenstrasse 5D-82024 TAUFKIRCHEN]. The cells were subcultured in DMEM with 10 percent FBS and $1 \times 10^{4} \mu / \mathrm{ml}$ antibiotics at a $5 \% \mathrm{CO}_{2}$ incubator at $37^{\circ} \mathrm{C}$. The cells at $80 \%$ confluence were subcultured into 96 well plates cytotoxicity experiments.

The BEAS-2B cell lines were grown overnight before exposure to AIONPs. The stock solution of AIONPs was prepared in double distilled water at the rate of $1 \mathrm{mg}$ AIONPs/ml DDW and diluted as per the experimental dosage $(0-100 \mathrm{mg} / \mathrm{l})$. Control cells were not exposed to AIONPs and were considered as controls.

2.6. 3-(4, 5-Dimethylthiazol-2-Yl)-2, 5-Diphenyltetrazolium Bromide (MTT) Test. The mitochondrial activity was determined by the MTT test [23]. MTT solution (100 $\mu \mathrm{l})$ was mixed to each well in a final concentration of $0.5 \mathrm{mg} / \mathrm{ml}$ and further left for incubation for an additional $3.5 \mathrm{~h}$. The formed formazan crystal was dissolved in isopropanol and the absorbance was measured at $570 \mathrm{~nm}$ using BioTek Epoch plate reader (BioTek Instruments, Winooski, VT, USA) and Gen5 software (version 1.09).

2.7. Statistical Analysis. All statistical analyses were performed using SPSS 26.0 software (IBM). Differences were analyzed using a one-way ANOVA test with the least significant difference test. Values of $* \mathrm{p}<0.05$ were considered statistically significant.

\section{Results and Discussion}

The confirmation of the formation of AIONPs was analyzed by various sophisticated instruments. Initially, Fe was leached out by treatment with strong sulphuric acid under sonication. The leachate rich in Fe gets precipitates with strong $\mathrm{NaOH}$, and the IONPs gets precipitated. Such a step also eliminates the impurities associated with the extracted ferrous fractions which are mainly $\mathrm{Ca}, \mathrm{Mg}, \mathrm{C}, \mathrm{Na}, \mathrm{Al}$ and $\mathrm{Si}$.

3.1. Raman and FTIR Analysis of AIONPs. Raman spectroscopy is an important technique for identifying the functional groups in the sample [43]. For IONPs, Raman spectroscopy plays an important role in phase identification. A typical Raman spectrum is shown for the AIONPs in Figure 1. The Raman spectrum shows two characteristic peaks for 


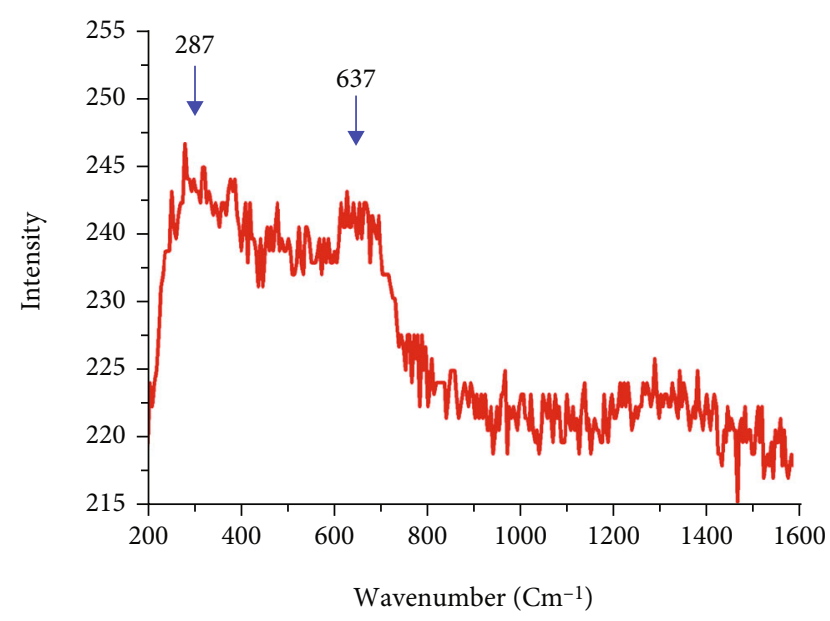

FIgURE 1: Raman spectra of amorphous iron oxide nanoparticles.

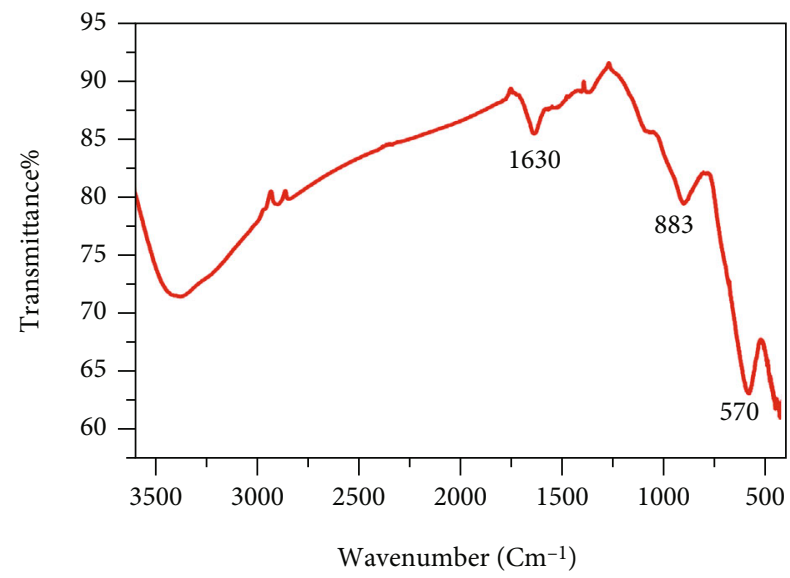

Figure 2: FTIR spectra of AIONPs.

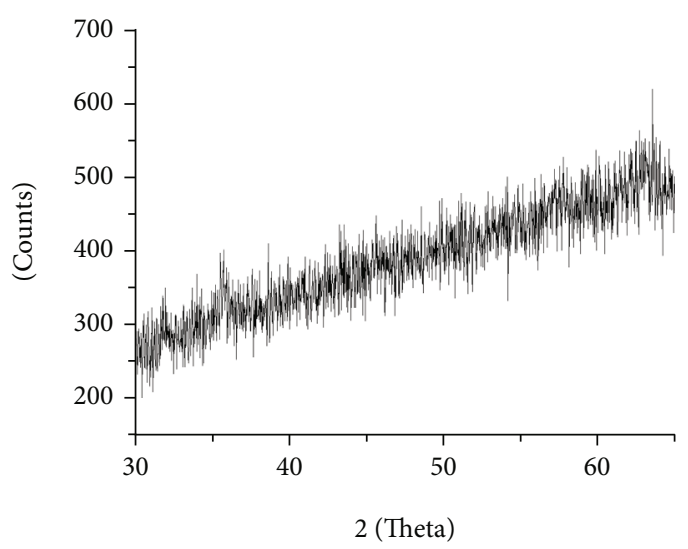

Figure 3: XRD diffractograph of amorphous iron oxide nanoparticles.

the synthesized AIONPs one at $287 \mathrm{~cm}^{-1}$ while the other at $637 \mathrm{~cm}^{-1}$. Both the bands are attributed to the $\mathrm{Fe}-\mathrm{O}$ band of the synthesized AIONPs. The bands in this region indicate the maghemite phases of the synthesized AIONPs. Similar results were also obtained by Yadav et al., 2020, [23, 44] where they synthesized AIONPs by ultrasonication method using ferrous as precursor. They have also obtained peaks at 273 and $691 \mathrm{~cm}^{-1}$ [45]. Besides this, there was an extra peak at $488 \mathrm{~cm}^{-1}$. This can be due to the oxidation of sample into maghemite because of the exposure of high-intensity laser onto the sample [46].

A typical FTIR spectrum of AIONPs is shown in Figure 2, where the band in the region of $450-900 \mathrm{~cm}^{-1}$ are assigned to the $\mathrm{Fe}-\mathrm{O}$ bond in the samples. Besides this, it may also be due to the presence of other metal oxide bonds present as impurities in the samples. The band at $1630 \mathrm{~cm}^{-1}$ and a broad-band near $3400 \mathrm{~cm}^{-1}$ is assigned to the $\mathrm{OH}$ group of a $\mathrm{H}_{2} \mathrm{O}$ molecule/or $\mathrm{Fe}(\mathrm{OH})_{3}$ present in the sample [47], whose results are in close agreement with Yadav et al., 2020 [48], where $\mathrm{Fe}-\mathrm{O}$ bands were obtained in the range of $400-900 \mathrm{~cm}^{-1}$, and water molecule band at 1660 and $3428 \mathrm{~cm}^{-1}[6,26]$. A small band near $2800 \mathrm{~cm}^{-1}$ is could be due to the adsorption of atmospheric $\mathrm{CO}_{2}$ by the sample as reported by numerous investigators in the literature [49].

3.2. Phase Identification of AIONPs by XRD. A typical XRD pattern of AIONPs is shown in Figure 3. There is no sharp crystalline peak in the pattern, which clearly shows that the synthesized IONPs are amorphous in nature $[6,50]$. A small peak at 32.4 and $36.5^{\circ}$ indicates the maghemite and magnetite phases in the samples which are satisfied with the results obtained by Yadav et al., 2020 [6] by sonochemical method, where they also got two peaks one at 34.5 and $36.8^{\circ}$ for magnetite [6]. A small peak at $43^{\circ}$ and $64^{\circ}$ is attributed to the calcite or carbonate phases and reflection peak of maghemite, respectively [51]. Since the parent material i.e. incense sticks ash, have calcite phases that remain associated with extracted ferrous fractions. Expect this, no significant peak is visible in the sample which the purity of the samples from other phases from ISA [6].

3.3. FESEM Analysis for Morphological Investigation. The FESEM micrographs of AIONPs is shown in Figure 4(a)-4 (d) at different resolutions. Figure 4(a)-4(b) shows that the particles large in shape whose size is in microns, aggregated together to form lumps. While, Figure 4(c), shows the presence of rod-shaped particles in the core of the lump, whose size varies from $80-200 \mathrm{~nm}$. Such individual rod-shaped particles are aggregated together to form spherical shaped micron-sized particles 1-2 microns. Since here no capping agent was used, so AIONPs are showing huge aggregation. Moreover, the aggregation of AIONPs is also due to the inherent property of IONPs [52]. Besides this, the particles have depositions of numerous white-coloured small particles over the surface. Such white small particles depositions are clearly visible in Figure 4(d) which could be the carbon present in the samples. Similar spherical and cuboidal shaped AIONPs were also obtained by Yadav et al., 2020 [6] and Ghanbari et al., $2014[53,54]$ by the sonochemical method. Yadav et al., 2020 [6] also reported the depositions of smaller white colored particles on the surface of rod/cuboidal shaped particles. Figure 4(e) exhibits the EDS spot, while Figure 4(f) shows the EDS spectra [6] of the synthesized AIONPs which have major spectra for $\mathrm{O}$ and Fe which confirms the formation of pure AIONPs. While, there are peaks for carbon 


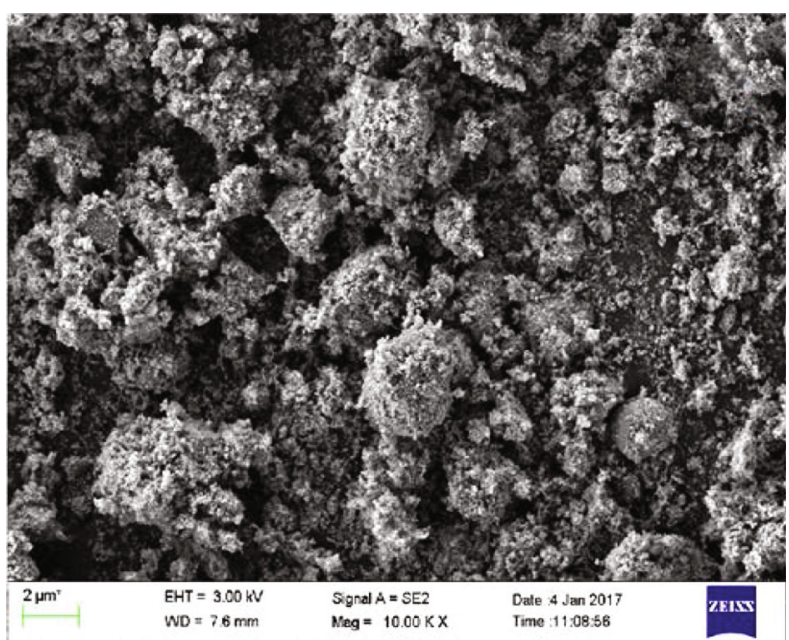

(a)

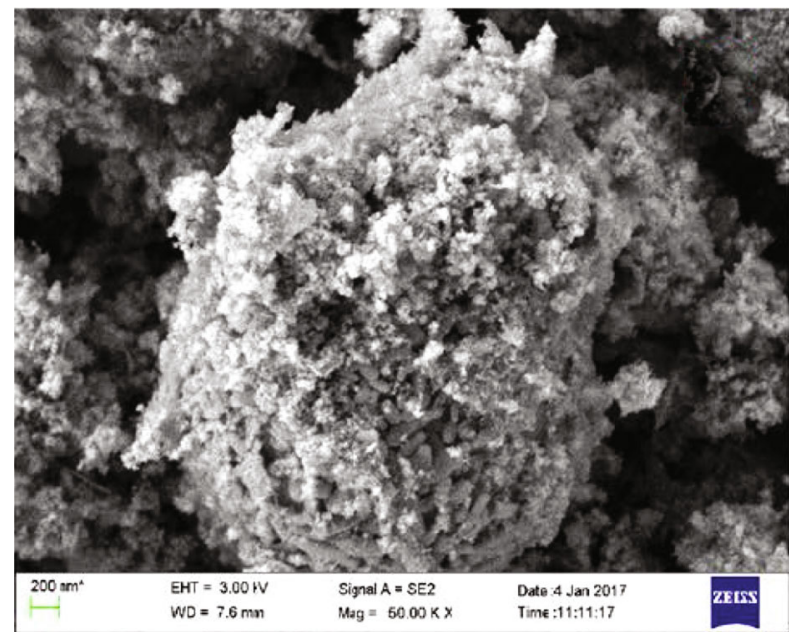

(c)

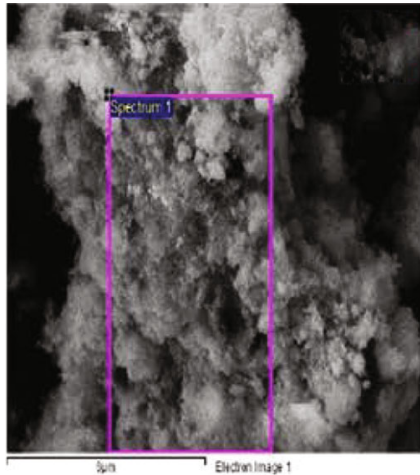

(e)

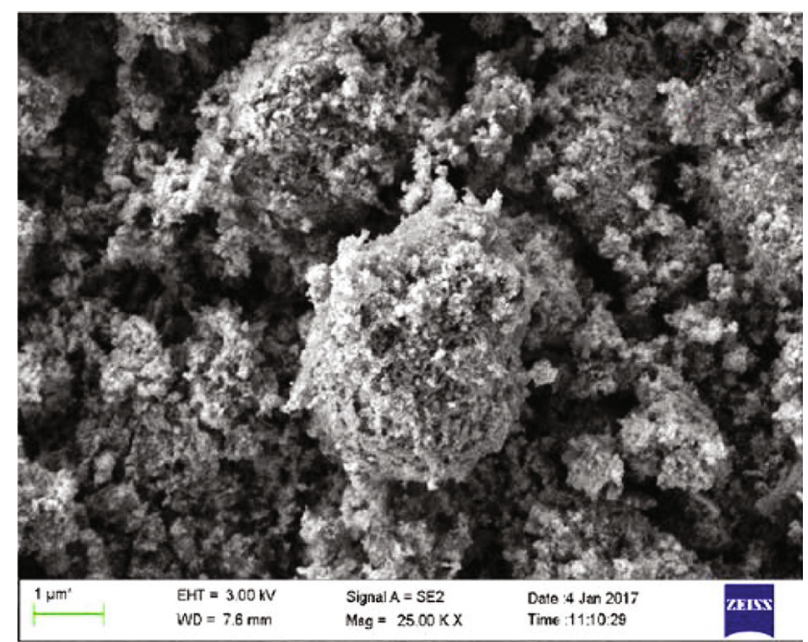

(b)

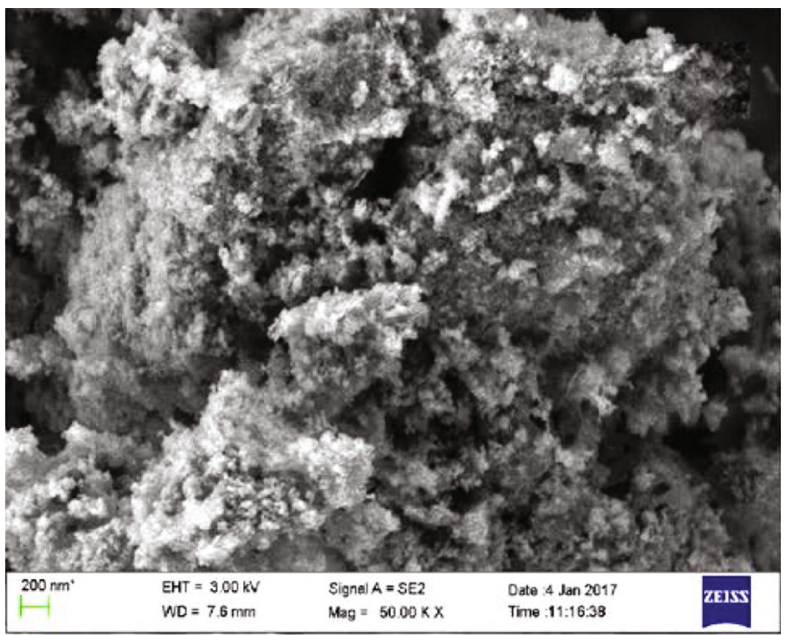

(d)

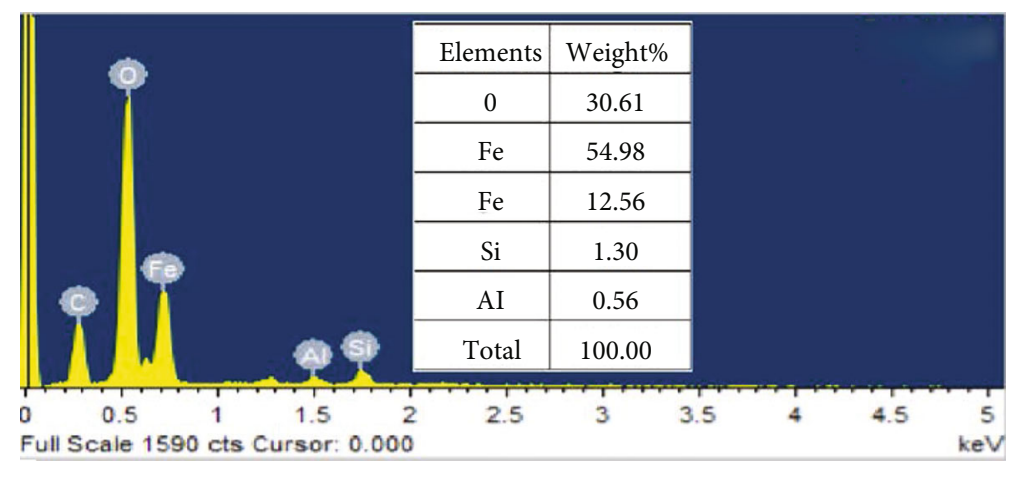

(f)

FIgure 4: FESEM micrographs of AIONPs (A-D), EDS spot (E) and EDS spectra and elemental Table (F).

which is 12.56 percent, which remained as an impurity from the initial sample. Besides this, the EDS spectra have minor peaks for $\mathrm{Si}$ and $\mathrm{Al}$ i.e. 1.30 and $0.56 \%$, respectively, as an impurity in the samples. This is so because the ferrous fractions are mainly present as a complex of ferro-aluminosilicate in the ISA. Moreover, after $\mathrm{Ca}, \mathrm{Si}$ and $\mathrm{Al}$ are present in the highest amount as metals in the ISA.
3.4. TEM Analysis of AIONPS. TEM images in Figure 5(a)-5 (d) of AIONPS are shown at different resolutions. Figure 5 (a) at $100 \mathrm{~nm}$ scale shows spherical and rod-shaped particles of sizes below $100 \mathrm{~nm}$. The spherical particles sizes are varying from $10-40 \mathrm{~nm}$, while rod-shaped particle length is 30 $60 \mathrm{~nm}$ and width $5-15 \mathrm{~nm}$. The spherical shaped particles are more dominant than the rod-shaped particles. Since 


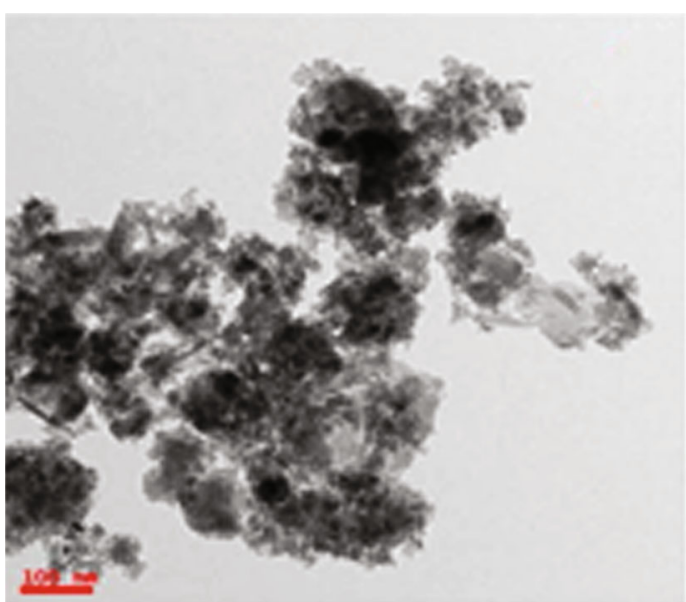

(a)

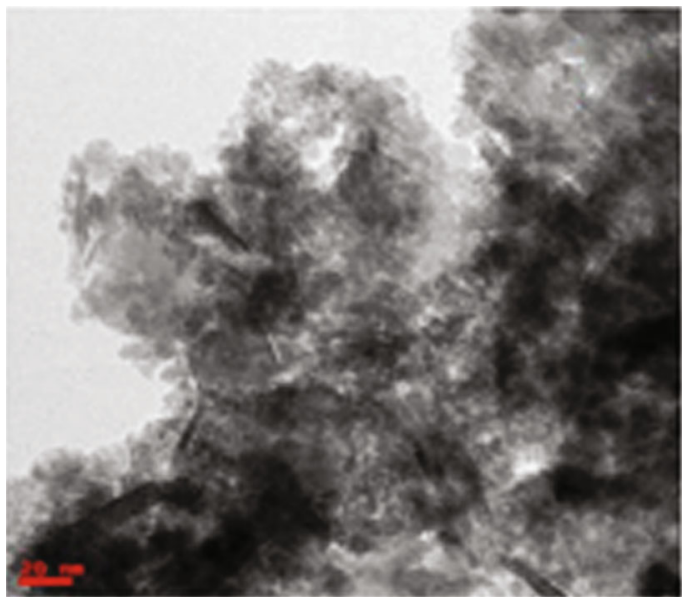

(c)

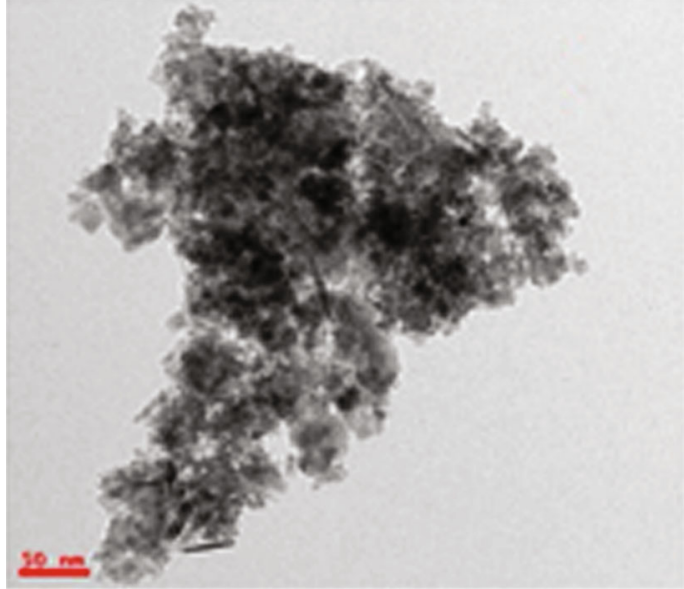

(b)

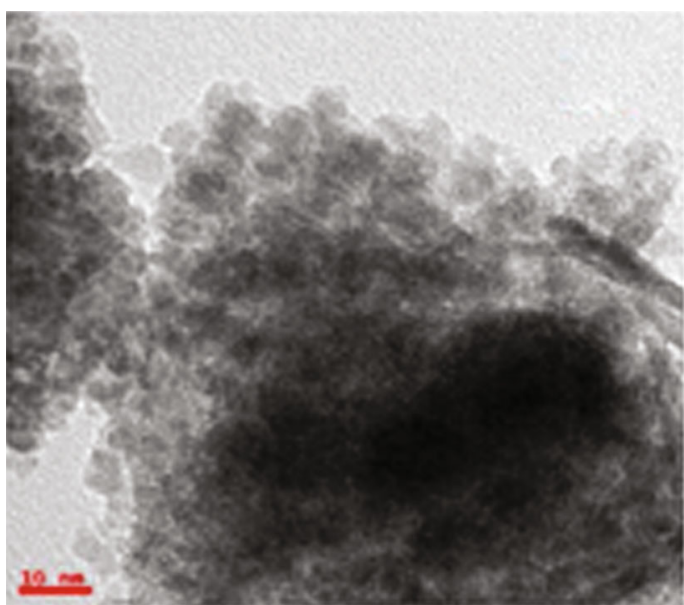

(d)

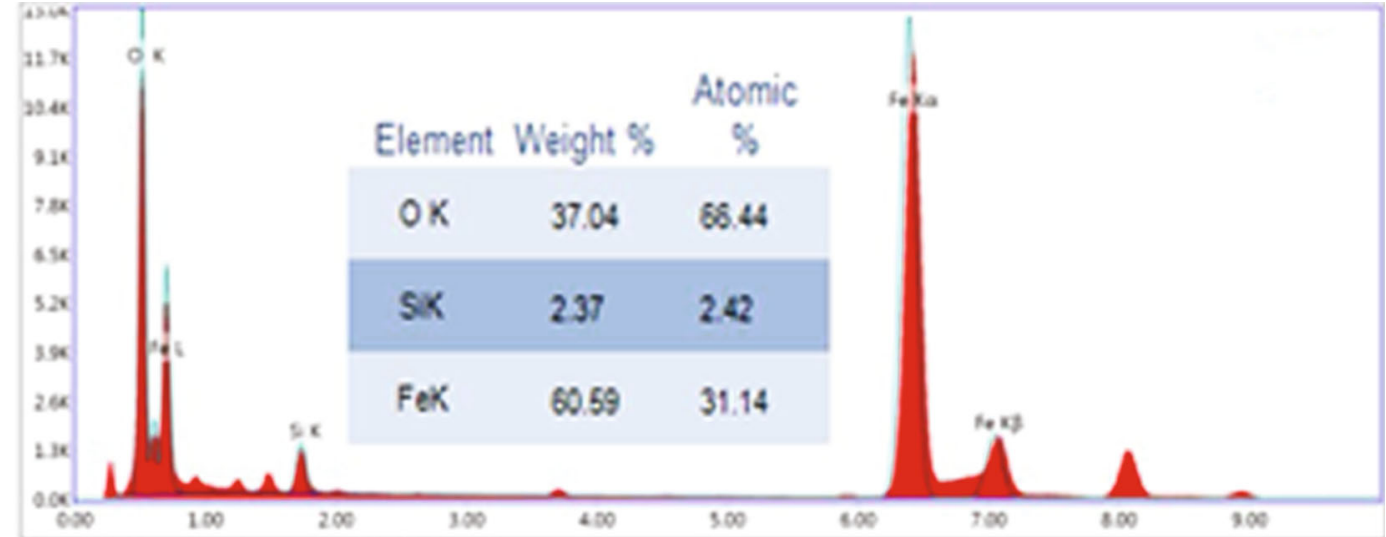

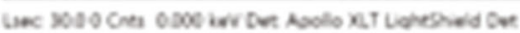

(e)

Figure 5: HRTEM images of AIONPs (A-D), and EDS spectra and elemental Table (E).

there is no capping agent and small size, adds to the aggregation tendency of the AIONPs. Similar, morphology for the amorphous IONPS was also reported by Pinkas et al., [55]. While Figure 5(b) at $50 \mathrm{~nm}$ scale also shows both spherical and rod-shaped particles. The dark colored particles are electron-rich particles, i.e. iron-rich regions whereas bright colored particles are carbon-rich particles. The appar- ent morphology was also agree well with the information revealed by FESEM. While Figure 5(c) shows HRTEM images at a $20 \mathrm{~nm}$ scale, where the spherical particles are more dominant in comparison to the rod-shaped particles. Besides this, there is more, brighter area which indicates the carbon-rich regions, which were deposited on the surface of AIONPs in FESEM images. In Figure 5(d), HRTEM 


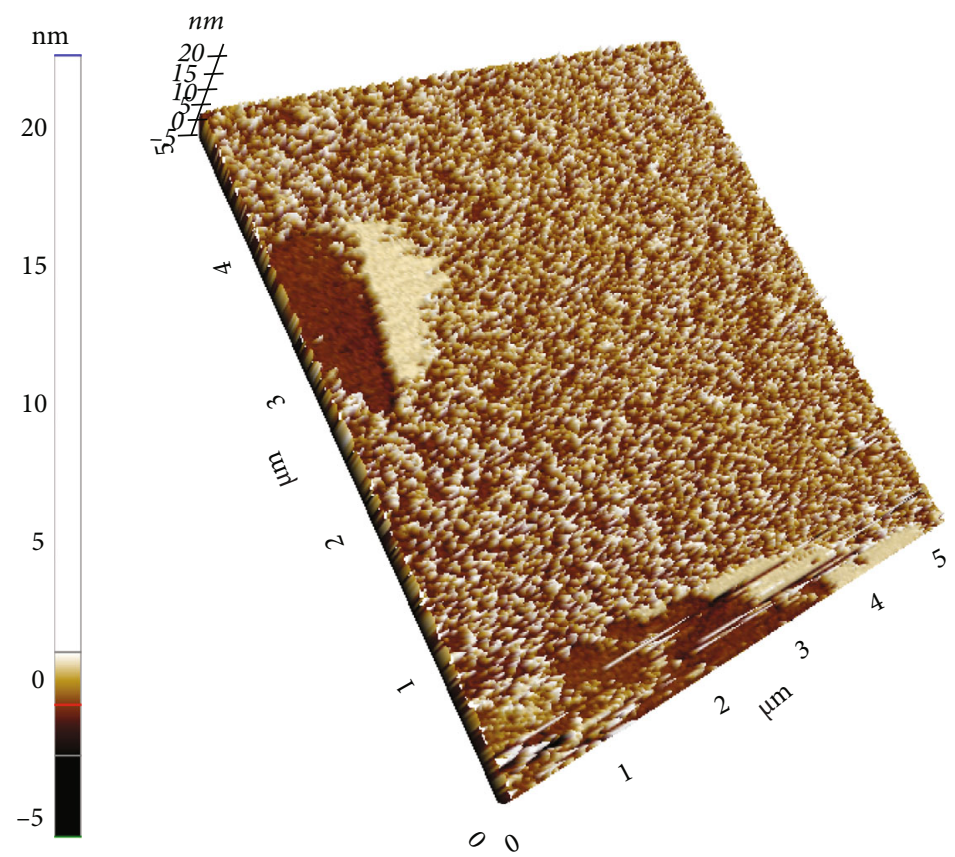

\begin{tabular}{|l|l|}
\hline File name & 180203Topography018 \\
Head mode & NC-AFM \\
Source & Topography \\
Data width & $256(\mathrm{pxl})$ \\
Data height & $256(\mathrm{pxl})$ \\
Xscan size & $5(\mu \mathrm{m})$ \\
Yscan size & $5(\mu \mathrm{m})$ \\
Scan rate & $1(\mathrm{HZ})$ \\
Z servo gain & $1.64(\mathrm{~nm})$ \\
Amplitude & $2.28(\mathrm{~nm})$ \\
Set point & $238.09 \mathrm{E} 3(\mathrm{~Hz})$ \\
Sel.Frequency & $100(\%)$ \\
Drive & 1 \\
\hline
\end{tabular}

FiguRE 6: AFM microscopy of amorphous iron oxide nanoparticles.

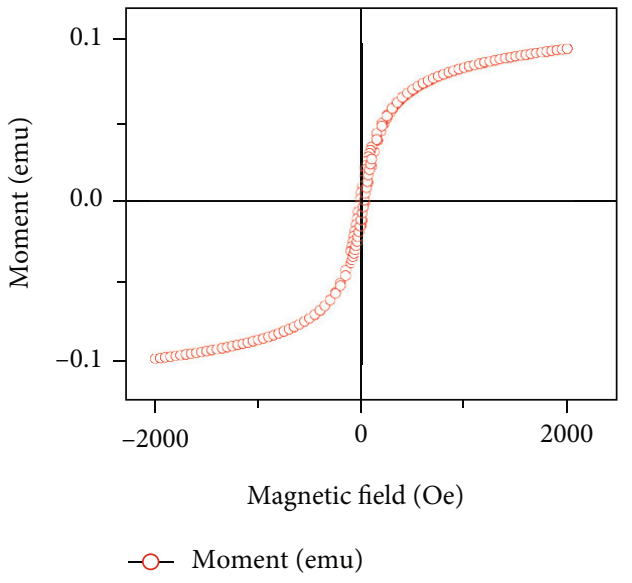

Figure 7: Magnetic strength of AIONPs.

images at a $10 \mathrm{~nm}$ scale show spherical shaped particles and brighter areas, which indicates that the region is again spherical particle dominant. Besides this three is only one or two dark rod-shaped particles which are AIONPs. The darker areas are electron-rich while the brighter areas are carbonrich areas. Figure 6(e) shows the EDS spectra and elemental table of the synthesized AIONPs. The EDS spectra clearly show major peaks of $\mathrm{O}$ and $\mathrm{Fe}$, which confirms the formation of IONPs. The presence of a small peak of $\mathrm{Si}$ and $\mathrm{Al}$ indicates the only impurity in the sample as the $\mathrm{Si}$ and $\mathrm{Al}$ was associated with the parent sample. Besides this, there were peaks for $\mathrm{Cu}$ and $\mathrm{C}$ also, which was contributed from the carbon-coated copper grids also, besides from the sample.
3.5. Three Dimensional Structure of AIONPs by AFM. To confirm the topographical features of the as-synthesized nanoparticles, an AFM study was carried for the AIONPs samples at RT. It is clearly observed that the crystalline solid particles are scattered on the scanned area Figure 6. The AIONPs is showing distorted globular structures as the samples were prepared under the co-precipitation method and annealed at $60^{\circ} \mathrm{C}$. These morphological findings are wellmatched with the TEM results as it has shown a clear dense scattered particle in TEM micrographs.

3.6. PPMS Study for Magnetic Features of AIONPs. The PPMS are used to reveal the magnetic features of a magnetic material. The synthesized AIONPs from ferrous fractions of ISA was analyzed to identify the magnetic strength. The magnetization against the applied magnetic field $(\mathrm{M}-\mathrm{H})$ curve of AIONPs was conducted at RT and the obtained graph is shown in Figure 7. The applied magnetic field was -2000 to +2000 against the emu, -1 to +1 . The thin area of the loop indicates that the particle is superparamagnetic in nature. Since the hysteresis is disappeared quickly in the small remanence, and coercivity (Hc), so it indicates the absence of long term dipole-dipole interactions among the assemblies of superparamagnetic NPs [56]. Moreover, the obtained loop is sigmoidal in shape which is the trademark feature of nanoparticles with a small magnetic field [57]. The saturation magnetization (Ms) reaches almost saturation after reaching 0.1 value. The Ms Value of the AIONPs is $2.25 \mathrm{emu} / \mathrm{g}$, the remnant magnetization (Mr) was $0.32 \mathrm{emu} / \mathrm{g}$ and the coercivity $(\mathrm{Hc})$ was $4.5 \mathrm{G}$, which is in satisfactory with the results obtained by Cheng et al., [58] and Mamani et al., [59] for IONPs synthesized by sonochemical and another method [26]. 


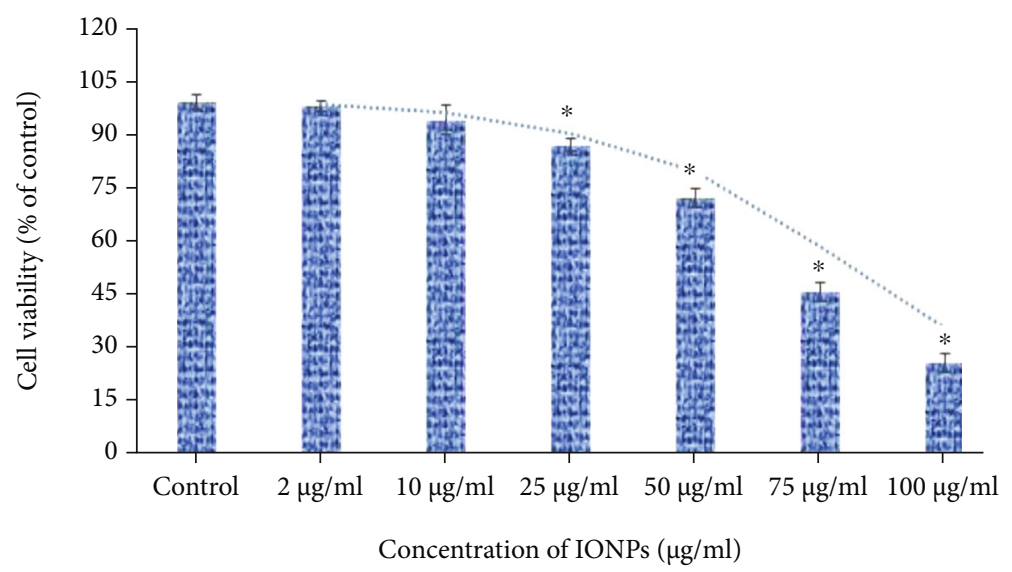

FIGURE 8: Effects of AIONPs on cell viability of BEAS-2B) cell line for $24 \mathrm{~h}$. Each value represents the average SE of three experiment $\mathrm{n}=3 *$ $\mathrm{p}<0.5$ versus control.

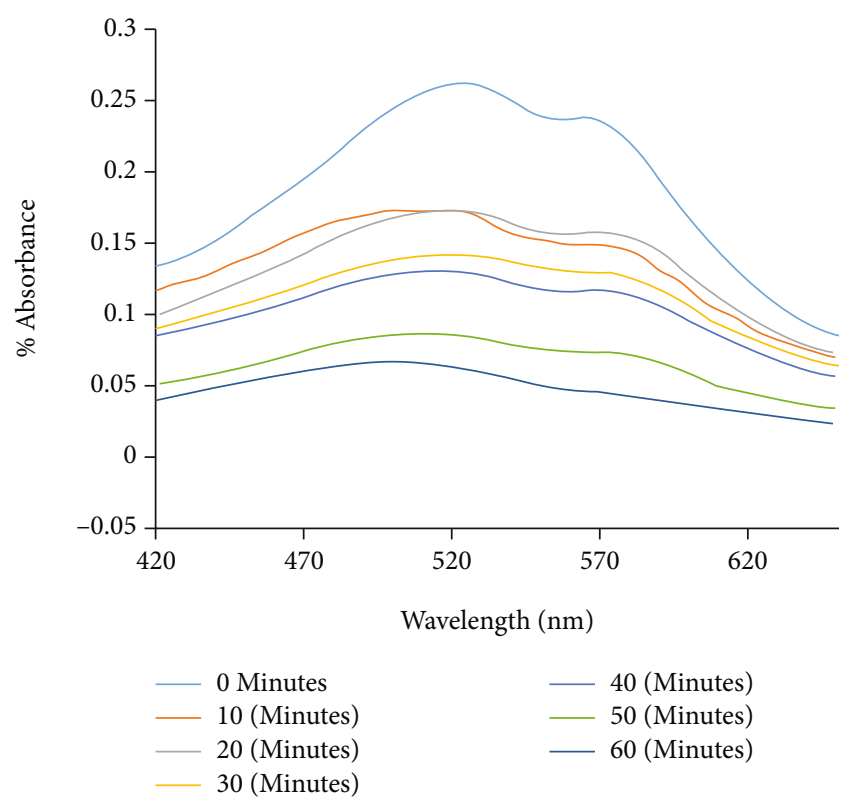

FIGURE 9: The percentage absorbance of CR dye by two mg AIONPs.

3.7. Cytotoxicity. The effect of AIONPs on the cell viability of BEAS-2B cell line for $24 \mathrm{~h}$ was determined by the MTT test. The cell viability result was represented in Figure 8. AIONPs affected the cell viability of the BEAS-2B cell line in a dosedependent manner but the maximum reduction of cell viability was observed at $100 \mu \mathrm{g} / \mathrm{ml} \mathrm{NPs}$. (Figure 8 ). The cytotoxicity of AIONPs $(2,10,25,50,75$ and $100 \mu \mathrm{g} / \mathrm{ml})$ was observed $98 \%, 93 \%, 82 \%, 75 \%, 45 \%$, and $24 \%$ for $24 \mathrm{~h}$ in BEAS-2B cell line (Figure 8).

3.8. Remediation Study of Congo Red Dye. Congo red dye is very toxic for the flora and fauna, so here it was remediated with respect to time by batch adsorption study. About $5 \mathrm{mg}$ of CR was dissolved in $200 \mathrm{ml}$ double distilled water as a source of wastewater. The $\mathrm{pH}$ of the solution was slightly acidic i.e. 6.5. About $2 \mathrm{mg}$ of AIONPs was added into the $200 \mathrm{ml}$ aqueous solution of CR. The CR dye aqueous solu- tion was in a $250 \mathrm{ml}$ beaker, which was placed on a magnetic stirrer, along with agitation at $400 \mathrm{rpm}$. Firstly, about $5 \mathrm{ml}$ sample was collected at the 0 minute time interval. After every 10 minutes of interval, an aliquot (2-3) ml was collected for one hour in a glass vial. The absorbance of the CR dye by $2 \mathrm{mg}$ AIONPs with respect to time was analyzed by the UV-Vis spectrophotometer shown in Figure 9. The percentage absorption of $\mathrm{CR}$ with respect to time was calculated by this formula:-

$$
\% \boldsymbol{R}=100 x\left(A_{0}-A_{t}\right) / A_{0}
$$

The CR removal percentage was calculated according to equation (1), where $A_{0}$ is the absorbance at $t=0$ and $A_{t}$ is the absorbance at time $=t$. Both the observations were measured at $497 \mathrm{~nm}$. Since the Congo red dye have maximum absorption at $497 \mathrm{~nm}$, so all the aliquot of the sample was analyzed in the nearby range of $497 \mathrm{~nm}$ in order to find the decrease or increase in the dye concentration.

The highest concentration of CR dye in the aqueous solution was at 0 , minutes in the initial sample, where there was no removal percentage at that time. The conc. of the CR dye in the samples continuously decreased as observed from the UV analysis except at 20 minutes at which the concentration slightly increased.

The removal percentage of CR dye is shown in Figure 10, where there is $0 \%$ degradation at 0 minutes while after 10 minutes it was $27.42 \%$, after twenty minutes it was $30.37 \%$, after 30 minutes it was $41.77 \%$, after 40 minutes it was $47.25 \%$, after 50 minutes it was $64.97 \%$ and after 60 minutes the removal percentage reached to maximum i.e. $72.99 \%$. So, there was continuous, removal of $\mathrm{CR}$ dye or adsorption of CR dye from the aqueous phase onto the AIONPs. Further incubation did not result in any further absorption thus the experiment was terminated after 60 minutes of observation.

Sri et al., 2021 [60] synthesized AIONPs of size 80$120 \mathrm{~nm}$ by the chemical route and used them for the removal of Rhodamine dye and reported efficiency of about $96.06 \%$ within $30 \mathrm{~min}$, under UV light [60]. Jain et al., 2020 [28] used ISA having pore volume 


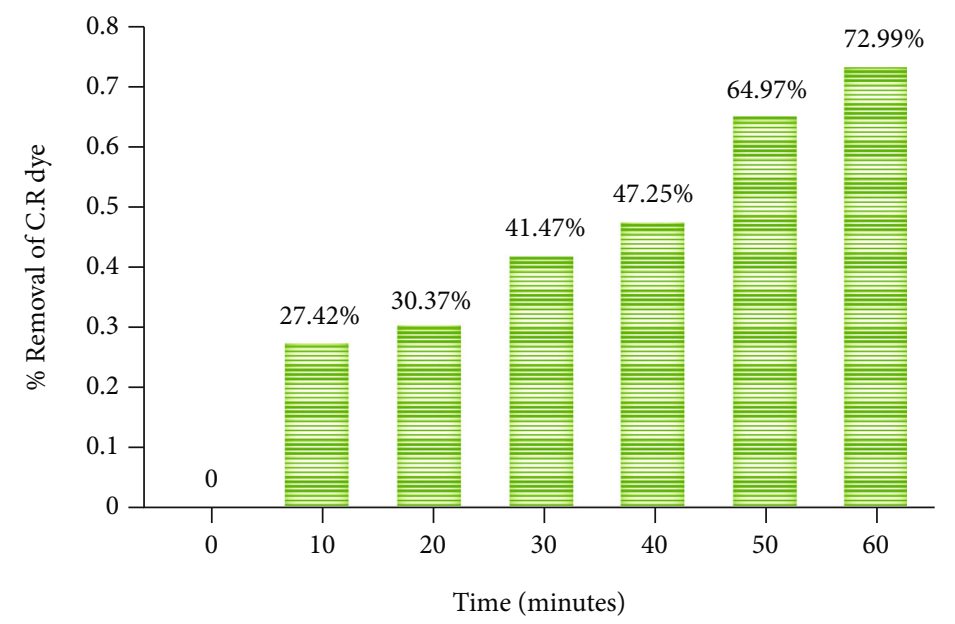

Figure 10: Percentage removal of CR dye.

$\left(0.0118 \mathrm{~cm}^{3} \mathrm{~g} / \mathrm{l}\right)$ and pore diameter $(21.02 \mathrm{~nm})$ for the removal of Victoria blue dye by batch adsorption method. The average size of ISA particles was $293.2 \mathrm{~nm}$, which showed maximum dye uptake up to $105.57 \mathrm{mg} / \mathrm{g}$. They concluded that temperature has positive effect on the adsorption efficiency of dye by the ISA [28].

The adsorption process exhibited that the AIONPs synthesized from ISA waste could act as an efficient and economical adsorbent for the remediation of CR dye from wastewater. If the adsorption process continued further, then the removal percentage might have reached $100 \%$ also. But here we have stopped our adsorption reaction after one hour only. Since the $\mathrm{pH}$ of the wastewater was slightly acidic, so the AIONPs have positive charges on their surfaces. While the CR dye has negative charges on their surfaces due to its acidic nature $[61,62]$, so, it is being attracted to the positively charged surface of AIONPs in the wastewater [63, 64]. Zhang et al.,2014 [65] developed a novel chitosan/ alginate sponge using freeze dry method and employed it for the removal of Congo red from aqueous medium. Based on the experimental result investigators reported that $0.1 \mathrm{~g}$ of adsorbent has high removal efficiency (98.97\%) for Congo red. Further, they also concluded that the adsorption of CR dye is comparatively better in acidic conditions than the basic conditions. Moreover, the CR dye adsorption equilibrium was achieved within 120 minutes of contact time. Investigators found that by increasing the initial concentration of CR dye, more adsorption of dye takes place [63]. While, if the $\mathrm{pH}$ reaches alkaline then the surface of AIONPS will have negative charges while the already negatively charged dye will be repelled so the efficiency of adsorption of CR dye by the adsorbent will be reduced [66]. Rani et al., 2017 [41] reported the utilization of coconut residual fiber (CRF), which is left after the extraction of coconut oil, for the removal of CR dye from the wastewater. The investigators concluded that the adsorption reaction was non-spontaneous, exothermic and followed pseudofirst order kinetics. Further, CRF as a potential biosorbent removed $\mathrm{CR}$ dye with a maximum adsorption capacity of
$128.94 \mathrm{mgg}^{-1}$ at room temperature. Lafi et al., 2018 [63] studied the removal of CR dye from both acidic and basic aqueous solutions and reported desorption of CR dye almost up to $90 \%$ after 6 cycles [63]. Moreover, here the CR dye aqueous solution was prepared in the laboratory so, when the textile or effluent based wastewater will be used then there will be the presence of various types of organic and inorganic pollutants [67-69], which will compete for the limited adsorption sites present on the surface of AIONPs [44, 70, 71]. So, ultimately the removal efficiency of CR dye will decrease in that situation. Since the wastewater was heterogeneous in nature, so similar competition among pollutants was observed [72]. Moreover, there was a higher amount of iron requirement for the remediation purpose in comparison to the conventional process.

\section{Future Prospects of Study}

Since the load for production of IONPs in the current industries are increasing to meet the supply for the nanoparticles due to their wide applications in biomedical and environmental remediation. So, the reliability of ISA like waste material for the production of AIONPs will reduce the burden on the current industries. Moreover, the product will be much economical and at the same time, the processing of ISA waste will reduce the solid waste and ultimately water pollution associated with its disposal into the rivers or other water bodies. So, such types of studies will help in providing an economical nano-adsorbent value-added material out of the waste. Moreover, in future, such IONPs will be used for the remediation of heavy metals, pesticides and other pollutants from the wastewater. Authors, further study will involve the effect of dosage, the effect of temperature and $\mathrm{pH}$ on the removal efficiency of not only CR dye but also numerous other hazardous dyes. Moreover, further study will also focus on the reusability of the adsorbent to reduce the final cost of adsorption, since AIONPs could easily be recovered by using an external magnet. In addition to this, studies can be related to medicine especially as an 
economical drug carrier and in agriculture for sustainable release of fertilizers to the plants. Moreover, the recovery of calcium oxides, silica, alumina and carbon particles from such ISA waste will open a new horizon in the field of processing of ISA waste as to date very few studies are available in the scientific domain. Such studies will attract the attention of scientific communities towards the ISA waste especially in Southeast Asian countries, and some of the Gulf countries, where incense sticks or other incense products are widely used at religious places. ISA will prove to be a resource material for the recovery of value-added materials in future.

\section{Conclusion}

Incense sticks ash is an emerging waste that was considered an orphan for a long time due to their non-attention and no known significance applications. The disposal of ISA into the River or in water bodies not only leads to water pollution but also challenges a potential threat to the living being. Here, we have suggested recovery of ferrous fractions from ISA which are impure due to the presence of $\mathrm{Al}, \mathrm{C}, \mathrm{Ca}$ and Si. So, further, we have suggested a method for the synthesis of AIONPs, of size $10-80 \mathrm{~nm}$ as revealed by the TEM. The particles were spherical and rod-shaped, amorphous in nature as confirmed by the XRD. The synthesized AIONPs was found suitable and efficient for the removal of CR dye from the aqueous phase at room temperature. Also, AIONPs induced cytotoxicity on human lung cells. Such type applications of iron oxide nanoparticles synthesized from waste material not only remediates pollution in the form of solid waste, biological application but also act as an economical nano adsorbent for dye removal.

\section{Data Availability}

The data sets used and analyzed during the current study are available within the article only.

\section{Conflicts of Interest}

All authors declare that there is no conflict of interest.

\section{Acknowledgments}

This work was funded by Researchers Supporting Project number (RSP-2021/165), King Saud University, Riyadh, Saudi Arabia. Also, the authors would like to acknowledge P P Savani University, Surat, India and St. Xavier's College, Nepal.

\section{References}

[1] I. Capek, "Chapter 1 Nanotechnology and nanomaterials," in Studies in Interface Science, I. Capek, Ed., vol. 23, pp. 1-69, Elsevier, 2006.

[2] I. Khan, K. Saeed, and I. Khan, "Nanoparticles: properties, applications and toxicities," Arabian Journal of Chemistry, vol. 12, pp. 908-931, 2019.
[3] A. Iqbal, K. Iqbal, B. Li, D. Gong, and W. Qin, "Recent advances in iron nanoparticles: preparation, properties, biological and environmental application," Journal of Nanoscience and Nanotechnology, vol. 17, pp. 4386-4409, 2017.

[4] P. Nagore, S. Ghotekar, K. Mane, A. Ghoti, M. Bilal, and A. Roy, "Structural properties and antimicrobial activities of Polyalthia longifolia leaf extract-mediated $\mathrm{CuO}$ nanoparticles," BioNanoScience, vol. 11, pp. 579-589, 2021.

[5] V. Cardoso, A. Francesko, C. Ribeiro, M. Bañobre-López, P. Martins, and S. Lanceros-Méndez, "Advances in magnetic nanoparticles for biomedical applications," Advanced Healthcare Materials, vol. 7, article 1700845, 2018.

[6] V. K. Yadav, D. Ali, S. H. Khan et al., "Synthesis and characterization of amorphous iron oxide nanoparticles by the Sonochemical method and their application for the remediation of heavy metals from wastewater," Nanomaterials, vol. 10, no. 8 , p. $1551,2020$.

[7] T. I. Shabatina, O. I. Vernaya, V. P. Shabatin, and M. Y. Melnikov, "Magnetic nanoparticles for biomedical purposes: modern trends and prospects," Magnetochemistry, vol. 6, p. 30, 2020.

[8] G. Gnanamoorthy, D. Ali, V. K. Yadav, G. Dhinagaran, K. Venkatachalam, and V. Narayanan, "New construction of $\mathrm{Fe}_{3} \mathrm{O}_{4} / \mathrm{rGO} / \mathrm{ZnSnO}_{3}$ nanocomposites enhanced photoelectro chemical properties," Optical Materials, vol. 109, article 110353, 2020.

[9] S. Raina, A. Roy, and N. Bharadvaja, "Degradation of dyes using biologically synthesized silver and copper nanoparticles," Environmental Nanotechnology, Monitoring \& Management, vol. 13, article 100278, 2020.

[10] V. K. Yadav and M. H. Fulekar, "Biogenic synthesis of maghemite nanoparticles $(\gamma$-Fe2O3) using Tridax leaf extract and its application for removal of fly ash heavy metals (Pb, cd)," Materials Today: Proceedings, vol. 5, pp. 20704-20710, 2018.

[11] J. H. Kim, G. D. Park, and Y. C. Kang, “Amorphous iron oxide-selenite composite microspheres with a yolk-shell structure as highly efficient anode materials for lithium-ion batteries," Nanoscale, vol. 12, pp. 10790-10798, 2020.

[12] N. K. Chowdhury and B. Bhowmik, "Micro/nanostructured gas sensors: the physics behind the nanostructure growth, sensing and selectivity mechanisms," Nanoscale Advances, vol. 3, pp. 73-93, 2021.

[13] J. Jin, Y. Zhang, G. Li, Z. Chu, and G. Li, "Synthesis and enhanced gas sensing properties of iron titanate and copper titanate nanomaterials," Materials Chemistry and Physics, vol. 249, article 123016, 2020.

[14] S. K. Verma, A. Thirumurugan, P. K. Panda et al., “Altered electrochemical properties of iron oxide nanoparticles by carbon enhance molecular biocompatibility through discrepant atomic interaction," Materials Today Bio, vol. 12, article 100131, 2021.

[15] V. K. Yadav, K. K. Yadav, G. Gnanamoorthy et al., "A novel synthesis and characterization of polyhedral shaped amorphous iron oxide nanoparticles from incense sticks ash waste," Environmental Technology and Innovation, vol. 20, article 101089, 2020.

[16] A. Zeleňáková, P. Hrubovčák, O. Kapusta et al., "Size and distribution of the iron oxide nanoparticles in SBA-15 nanoporous silica via SANS study," Scientific Reports, vol. 9, p. 15852, 2019. 
[17] N. D. Phu, D. T. Ngo, L. H. Hoang, N. H. Luong, N. Chau, and N. H. Hai, "Crystallization process and magnetic properties of amorphous iron oxide nanoparticles," Journal of Physics D: Applied Physics, vol. 44, no. 34, p. 345002, 2011.

[18] A. Ali, H. Zafar, M. Zia et al., "Synthesis, characterization, applications, and challenges of iron oxide nanoparticles," Nanotechnology, Science and Applications, vol. 9, pp. 49-67, 2016.

[19] J. Rieger, V. Colla, I. Matino et al., "Residue valorization in the iron and steel industries: sustainable solutions for a cleaner and more competitive future Europe," Metals, vol. 11, no. 8, p. 1202, 2021.

[20] E. Strzałkowska, "Morphology, chemical and mineralogical composition of magnetic fraction of coal fly ash," International Journal of Coal Geology, vol. 240, article 103746, 2021.

[21] K. E. Ekstroem, A. V. Bugten, C. van der Eijk, A. Lazou, E. Balomenos, and G. Tranell, "Recovery of iron and aluminum from bauxite residue by Carbothermic reduction and slag leaching," Journal of Sustainable Metallurgy, vol. 7, pp. 13141326, 2021.

[22] R. Arpita and B. Navneeta, "Silver nanoparticle synthesis fromPlumbago zeylanicaand its dye degradation activity," Bioinspired, Biomimetic and Nanobiomaterials, vol. 8, no. 2, pp. 130-140, 2019.

[23] N. Gupta, V. K. Yadav, K. K. Yadav et al., "Recovery of iron nanominerals from sacred incense sticks ash waste collected from temples by wet and dry magnetic separation method," Environmental Technology and Innovation, vol. 25, article 102150, 2022.

[24] V. K. Yadav, K. K. Yadav, J. Alam et al., "Transformation of hazardous sacred incense sticks ash waste into less toxic product by sequential approach prior to their disposal into the water bodies," Environmental Science and Pollution Research, 2021.

[25] V. K. Yadav, P. Malik, A. H. Khan et al., "Recent advances on properties and utility of nanomaterials generated from industrial and biological activities," Crystals, vol. 11, no. 6, p. 634, 2021.

[26] H. M. Ahmed, A. Roy, M. Wahab, B. H. Othman-Qadir, and T. B. Emran, "Applications of nanomaterials in agrifood and pharmaceutical industry," Journal of Nanomaterials, 2021.

[27] V. K. Yadav, G. Gnanamoorthy, M. M. S. Cabral-Pinto et al., "Variations and similarities in structural, chemical, and elemental properties on the ashes derived from the coal due to their combustion in open and controlled manner," Environmental Science and Pollution Research, vol. 28, pp. 32609-32625, 2021.

[28] S. N. Jain, S. R. Tamboli, D. S. Sutar, V. N. Mawal, A. A. Shaikh, and A. A. Prajapati, "Incense stick ash as a novel and sustainable adsorbent for sequestration of Victoria blue from aqueous phase," Sustainable Chemistry and Pharmacy, vol. 15, article 100199, 2020.

[29] J. A. Fuentes-García, A. Carvalho Alavarse, A. C. Moreno Maldonado, A. Toro-Córdova, M. R. Ibarra, and G. F. Goya, "Simple Sonochemical method to optimize the heating efficiency of magnetic nanoparticles for magnetic fluid hyperthermia," ACS Omega, vol. 5, pp. 26357-26364, 2020.

[30] G. Marchegiani, P. Imperatori, A. Mari et al., "Sonochemical synthesis of versatile hydrophilic magnetite nanoparticles," Ultrasonics Sonochemistry, vol. 19, pp. 877-882, 2012.
[31] Á. Prekob, G. Muránszky, I. Kocserha et al., "Sonochemical deposition of palladium nanoparticles onto the surface of $\mathrm{N}$ doped carbon nanotubes: a simplified one-step catalyst production method," Catalysis Letters, vol. 150, pp. 505-513, 2020.

[32] A. Gedanken, "Using sonochemistry for the fabrication of nanomaterials," Ultrasonics Sonochemistry, vol. 11, pp. 4755, 2004.

[33] M. S. Ramya Sankar and V. Sivasubramanian, "Application of statistical design to optimize the electrocoagulation of synthetic Congo red dye solution and predicting the mechanism," International journal of Environmental Science and Technology, vol. 17, pp. 1373-1386, 2020.

[34] M. M. Iqbal, M. Imran, T. Hussain et al., "Effective sequestration of Congo red dye with $\mathrm{ZnO} /$ cotton stalks biochar nanocomposite: MODELING, reusability and stability," Journal of Saudi Chemical Society, vol. 25, no. 2, article 101176, 2021.

[35] M. T. M. H. Hamad and M. S. S. Saied, "Kinetic studies of Congo red dye adsorption by immobilized aspergillus Niger on alginate," Applied Water Science, vol. 11, no. 2, p. 35, 2021.

[36] N. A. Alamrani and H. A. Al-Aoh, "Elimination of Congo Red Dye from Industrial Wastewater Using Teucrium polium L. as a Low-Cost Local Adsorbent," Adsorption Science \& Technology, vol. 2021, article 5728696, pp. 1-12, 2021.

[37] J. M. Jabar, Y. A. Odusote, K. A. Alabi, and I. B. Ahmed, "Kinetics and mechanisms of Congo-red dye removal from aqueous solution using activated Moringa oleifera seed coat as adsorbent," Applied Water Science, vol. 10, no. 6, p. 136, 2020.

[38] A. Ramamoorthy, S. Ravi, N. Jeddy, R. Thangavelu, and S. Janardhanan, "Natural alternatives for chemicals used in histopathology lab- a literature review," Journal of Clinical and Diagnostic Research, vol. 10, p. EE01-EE04, 2016.

[39] S. E. Setti, J. Raymick, J. Hanig, and S. Sarkar, "In vivo demonstration of Congo red labeled amyloid plaques via perfusion in the Alzheimer disease rat model," Journal of Neuroscience Methods, vol. 353, article 109082, 2021.

[40] M. Hernández-Zamora, F. Martínez-Jerónimo, E. CristianiUrbina, and R. O. Cañizares-Villanueva, "Congo red dye affects survival and reproduction in the cladoceran Ceriodaphnia dubia. Effects of direct and dietary exposure," Ecotoxicology, vol. 25, pp. 1832-1840, 2016.

[41] K. C. Rani, A. Naik, R. S. Chaurasiya, and K. S. M. S. Raghavarao, "Removal of toxic Congo red dye from water employing low-cost coconut residual fiber," Water Science and Technology, vol. 75, pp. 2225-2236, 2017.

[42] T. Sarkar, K. K. Bharadwaj, M. Salauddin, S. Pati, and R. Chakraborty, "Phytochemical characterization, antioxidant, anti-inflammatory, anti-diabetic properties, molecular docking, pharmacokinetic profiling, and network pharmacology analysis of the major Phytoconstituents of raw and differently dried Mangifera indica (Himsagar cultivar): an In vitro and In silico investigations," Applied Biochemistry and Biotechnology, vol. 194, pp. 950-987, 2021.

[43] K. V. Hackshaw, J. S. Miller, D. P. Aykas, and L. RodriguezSaona, "Vibrational spectroscopy for identification of metabolites in biologic samples," Molecules, vol. 25, no. 20, p. 25, 2020.

[44] V. K. Yadav, N. Choudhary, D. Ali et al., "Experimental and computational approaches for the structural study of novel ca-rich zeolites from incense stick ash and their application for wastewater treatment," Adsorption Science \& Technology, vol. 2021, article 6066906, pp. 1-12, 2021. 
[45] J. Shi, "Amorphous iron nanoparticles: special structural and physicochemical features enable chemical dynamic therapy for tumors," Nanomedicine, vol. 11, pp. 1189-1191, 2016.

[46] S. P. Schwaminger, C. Syhr, and S. Berensmeier, "Controlled synthesis of magnetic iron oxide nanoparticles: magnetite or Maghemite?," Crystals, vol. 10, no. 3, p. 214, 2020.

[47] J. Zhuang, M. Li, Y. Pu, A. Ragauskas, and C. Yoo, “Observation of potential contaminants in processed biomass using Fourier transform infrared spectroscopy," Applied Sciences, vol. 10, 2020.

[48] A. Roy, "Synthesis of silver nanoparticles from medicinal plants and its biological application: A review," Research \& Reviews in BioSciences, vol. 12, no. 4, p. 138, 2017.

[49] P. Pocasap, N. Weerapreeyakul, C. Junhom et al., "FTIR microspectroscopy for the assessment of mycoplasmas in HepG2 cell culture," Applied Sciences, vol. 10, no. 11, p. 3766, 2020.

[50] N. Ajinkya, X. Yu, P. Kaithal, H. Luo, P. Somani, and S. Ramakrishna, "Magnetic iron oxide nanoparticle (IONP) synthesis to applications: present and future," Materials, vol. 13, no. 20, p. 35, 2020.

[51] M. Coduri, P. Masala, L. Del Bianco et al., "Local structure and magnetism of $\mathrm{Fe} 2 \mathrm{O} 3$ Maghemite nanocrystals: the role of crystal dimension," Nanomaterials, vol. 10, no. 5, p. 867, 2020.

[52] A. A. Hernández-Hernández, G. Aguirre-Álvarez, R. CariñoCortés, L. H. Mendoza-Huizar, and R. Jiménez-Alvarado, "Iron oxide nanoparticles: synthesis, functionalization, and applications in diagnosis and treatment of cancer," Chemical Papers, vol. 74, pp. 3809-3824, 2020.

[53] N. Zhu, P. Yu, J. Niu et al., "Surface modification of magnetic iron oxide nanoparticles," Nanomaterials, vol. 8, no. 10, p. 810, 2018.

[54] D. Ghanbari, M. Salavati-Niasari, and M. Ghasemi-Kooch, "A sonochemical method for synthesis of $\mathrm{Fe} 3 \mathrm{O} 4$ nanoparticles and thermal stable PVA-based magnetic nanocomposite," Journal of Industrial and Engineering Chemistry, vol. 20, pp. 3970-3974, 2014.

[55] J. Pinkas, V. Reichlova, R. Zboril, Z. Moravec, P. Bezdicka, and J. Matejkova, "Sonochemical synthesis of amorphous nanoscopic iron(III) oxide from Fe(acac)3," Ultrasonics Sonochemistry, vol. 15, pp. 257-264, 2008.

[56] C. Nayek, K. Manna, G. Bhattacharjee, P. Murugavel, and I. Obaidat, "Investigating size- and temperature-dependent Coercivity and saturation magnetization in PEG coated Fe3O4 nanoparticles," Magnetochemistry, vol. 3, p. 15, 2017.

[57] R. G. D. Andrade, S. R. S. Veloso, and E. M. S. Castanheira, "Shape anisotropic iron oxide-based magnetic nanoparticles: synthesis and biomedical applications," International Journal of Molecular Sciences, vol. 21, p. 21, 2020.

[58] Z. Cheng, A. L. K. Tan, Y. Tao, D. Shan, K. E. Ting, and X. J. Yin, "Synthesis and characterization of iron oxide nanoparticles and applications in the removal of heavy metals from industrial wastewater," International Journal of Photoenergy, vol. 2012, Article ID 608298, 2012.

[59] J. B. Mamani, L. F. Gamarra, and G. E. Brito, "Synthesis and characterization of $\mathrm{Fe} 3 \mathrm{O} 4$ nanoparticles with perspectives in biomedical applications," Materials Research, vol. 17, no. 3, pp. 542-549, 2014.
[60] V. S. Sri, A. Manikandan, M. Mathankumar et al., "Unveiling the photosensitive and magnetic properties of amorphous iron nanoparticles with its application towards decontamination of water and cancer treatment," Journal of Materials Research and Technology, vol. 15, pp. 99-118, 2021.

[61] K. Litefti, M. S. Freire, M. Stitou, and J. González-Álvarez, "Adsorption of an anionic dye (Congo red) from aqueous solutions by pine bark," Scientific Reports, vol. 9, p. 16530, 2019.

[62] S. Chatterjee, N. Guha, S. Krishnan, A. K. Singh, P. Mathur, and D. K. Rai, "Selective and recyclable Congo red dye adsorption by spherical $\mathrm{Fe} 3 \mathrm{O} 4$ nanoparticles functionalized with 1,2,4,5-Benzenetetracarboxylic acid," Scientific Reports, vol. 10, p. 111, 2020.

[63] R. Lafi, I. Montasser, and A. Hafiane, "Adsorption of Congo red dye from aqueous solutions by prepared activated carbon with oxygen-containing functional groups and its regeneration," Adsorption Science \& Technology, vol. 37, pp. 160-181, 2019.

[64] N. U. M. Nizam, M. M. Hanafiah, E. Mahmoudi, A. A. Halim, and A. W. Mohammad, "The removal of anionic and cationic dyes from an aqueous solution using biomass-based activated carbon," Scientific Reports, vol. 11, p. 8623, 2021.

[65] Q. Zhang, M. Xie, X. Guo, L. Zeng, and J. Luo, "Fabrication and adsorption behavior for Congo red of chitosan and alginate sponge," Integrated Ferroelectrics, vol. 151, pp. 61-75, 2014.

[66] H. T. Ha, P. T. Phong, and T. D. Minh, "Synthesis of iron oxide nanoparticle functionalized activated carbon and its applications in arsenic adsorption," Journal of Analytical Methods in Chemistry, vol. 2021, 2021.

[67] D. A. Yaseen and M. Scholz, "Textile dye wastewater characteristics and constituents of synthetic effluents: a critical review," International journal of Environmental Science and Technology, vol. 16, pp. 1193-1226, 2019.

[68] T. Adane, A. T. Adugna, and E. Alemayehu, "Textile industry effluent treatment techniques," Journal of Chemistry, vol. 2021, Article ID 5314404, 2021.

[69] T. Shindhal, P. Rakholiya, S. Varjani et al., "A critical review on advances in the practices and perspectives for the treatment of dye industry wastewater," Bioengineered, vol. 12, pp. 70-87, 2021.

[70] A. A. Azzaz, S. Jellali, N. B. H. Hamed et al., "Photocatalytic treatment of wastewater containing simultaneous organic and inorganic pollution: competition and operating parameters effects," Catalysts, vol. 11, p. 855, 2021.

[71] N. Choudhary, V. K. Yadav, K. K. Yadav et al., "Application of green synthesized MMT/ag nanocomposite for removal of methylene blue from aqueous solution,” Water, vol. 13, 2021.

[72] T. C. Egbosiuba, A. S. Abdulkareem, A. S. Kovo et al., "Adsorption of $\mathrm{Cr}(\mathrm{VI}), \mathrm{Ni}(\mathrm{II}), \mathrm{Fe}(\mathrm{II})$ and $\mathrm{cd}(\mathrm{II})$ ions by KIAgNPs decorated MWCNTs in a batch and fixed bed process," Scientific Reports, vol. 11, p. 75, 2021. 